\title{
TRANSCULTURACIÓN E IDENTIDAD EN EL PENSAMIENTO DE FERNANDO ORTIZ, SU PERTINENCIA ANTE LA VISIÓN HEGEMÓNICA DE PODER
}

\author{
Andrés Lora Bombino ${ }^{67}$
}

RESUMEN: Homogeneizar, imponer una cultura como única y mejor, no reconocer las diferencias, es una herramienta de las estructuras verticales de poder, de un control social que se fundamenta en la vieja y acartonada dicotomía opresor-oprimido; en cambio, reconocer las heterogeneidades, las diferencias y alteridades, y por ende que la constitución de la cultura es compleja, potencialmente transcultural y con ello cambiante y transformativa, permite abrir nuevas perspectivas que, asimismo, nos acercan a una ética realista y con ello a la construcción de un mundo más justo con vidas más interesantes y dignas de ser disfrutadas. En nuestro país la obra de Fernando Ortiz es básica para los estudios de la identidad cubana, y en sentido general, para los estudios referidos a la cultura cubana, plasmados en libros, ensayos, artículos y conferencias de necesaria referencia para cualquier estudio sobre el tema. Pero su mayor aporte, desde el punto de vista de concepto, es la introducción del neologismo transculturación, para referirse al intercambio entre distintas culturas y así echar por tierra teorías que había minimizado o, en el mejor de los casos, convertido en "culturas menores", todo el rico legado cultural de Latinoamérica y el Caribe. La globalización neoliberal, la crisis económica actual y los cambios sucedidos en América Latina, así como la perenne lucha contra el capitalismo imperial de los Estados Unidos, hacen de este concepto en extremo útil para los estudios referidos a la identidad en todo el continente. El presente trabajo aborda la transculturación dentro del proceso identitario cubano, frente a la visón hegemónica de poder.

Palabras-clave: Transculturación; Fernando Ortiz; proceso identitario cubano.

${ }^{67}$ Doctorando en Literatura. Profesor en la Universidad Central Marta Abreu de Las Villas. Santa Clara. Villa Clara. Cuba. 
RESUMO: Homogeneizar, impor uma cultura como única e melhor, não reconhecer as diferenças, é uma ferramenta das estruturas verticais de poder, de um controle social que se fundamenta na velha e engessada dicotomia opressor-oprimido; no entanto, reconhecer as heterogeneidades, as diferenças e alteridades, e, por conseguinte, que a constituição da cultura é complexa, potencialmente transcultural e, com isso, cambiante e transformativa, permite abrir novas perspectivas que também nos aproximam de uma ética realista e, assim, da construção de um mundo mais justo, com vidas mais interessantes e dignas de serem desfrutadas. No nosso país, a obra de Fernando Ortiz é básica para os estudos de identidade cubana e, em geral, para os estudos relacionados com a cultura cubana, consubstanciado em livros, ensaios, artigos e conferências de referência necessária para qualquer estudo sobre o tema. No entanto, sua maior contribuição, do ponto de vista de conceito, é a introdução do neologismo transculturação, para se referir ao intercâmbio entre distintas culturas e, portanto, colocar por terra teorias que foram minimizados ou, na melhor das hipóteses, convertidas em "culturas menores" todo o rico legado cultural da América Latina e do Caribe. A globalização neoliberal, a atual crise económica e as mudanças ocorridas na América Latina e a luta constante contra o capitalismo imperial dos Estados Unidos, fazem este conceito extremamente útil para os estudos relacionados à identidade em todo o continente. O presente trabalho aborda a transculturação dentro do processo de identidade cubana, contra a visão hegemônica de poder.

Palavras-chave: Transculturação; Fernando Ortiz; processo identitário cubano.

El ensayo, tuvo siempre en nuestra Historia, desde el primer tercio del S XIX a intelectuales que estuvieron preocupados por el futuro de Cuba. No podemos olvidar, por mencionar algunos, Las Cartas a Elpidio y El Habanero del padre Félix Varela de cierta manera, poseen muchos elementos que podemos incluir dentro del género, aunque para entonces no era muy cultivado en lengua castellana.

De la situación histórica de la Colonia provenía, sin embargo, un ámbito propicio para la faena ensayística en cuanto esta representaba el vehículo adecuado donde volcar la actitud criticista de los escritores cubanos empeñados en una labor de servicio patriótico. Cuando se produce el advenimiento de la República en 1902, mantenían su producción crítica muchos de los escritores pertenecientes a la última 
promoción decimonónica. Ya hacia 1910 comienzan a destacarse los jóvenes escritores que forman la primera generación republicana.

En la cultura cubana del siglo XX, la personalidad y la obra de Fernando Ortiz poseen singular relieve. Figura principal en nuestro proceso social y político, sus numerosas obras revelan la multiplicidad de sus intereses intelectuales; la vasta obra emprendida, su ahincado esfuerzo en la investigación y el esclarecimiento de los más diversos componentes de nuestra nacionalidad. Forjador y animador de prestigiosas empresas e instituciones culturales, como la Institución Hispano-Cubana de Cultura. Su obra, de intrínsecos valores científicos, está enraizada en lo cubano, vinculada al desentrañamiento de nuestra composición social y la investigación de los aportes africanos a nuestra cultura, y a los fundamentos sociales y económicos de nuestra comunidad. Representa en Cuba republicana un continuador de las tareas fundamentales que los grandes cubanos del siglo XIX habían emprendido.

Ortiz dedica la mayor parte de su labor al estudio de la población negra y sus aportes a la cultura cubana. Sus investigaciones antropológicas y sociales sobre las creencias, las costumbres, los bailes y la música mulata lo llevan a escribir los cinco volúmenes Los instrumentos de la música afrocubana (1950-1955).

Dichos estudios no quedan en una mera indagación científica, pues están encaminados a lograr la mejor integración de Cuba. De ahí su concepto de cubana:"que es conciencia, voluntad, y raíz de patria", que se forma por los diversos factores humanos y culturales que se vinculan en nuestro país. Hombre de ideas liberales y progresistas, Ortiz se sitúa contra cualquier discriminación racial. Sobre el estático y falso concepto de raza colocará la definición dinámica de la cultura.

Comentar la obra enciclopédica de Fernando Ortiz Fernández (1881-1969), en pocas palabras, es prácticamente imposible. No escaparon a su curiosidad múltiple muchas de las ciencias del hombre: criminología, musicología, sociología, historia, derecho, economía, antropología, arqueología, folklore, lingüistica. La variedad de sus intereses intelectuales lo convirtieron en polígrafo y le valieron el título de Tercer Descubridor de Cuba, al decir de Juan Marinello.

Su labor, desplegada en algo más de sesenta años de su larga vida, encontró la cúspide en una decena de libros fundamentales para la cultura nacional: Los negros brujos (1906), Los negros esclavos (1916), Historia de la Arqueología indocubana (1922), Catauro de cubanismos (1923), 
Contrapunteo cubano del tabaco y el azúcar (1940), La africanía de la música folklórica de Cuba (1950), Los bailes y el teatro de los negros en el folklore de Cuba (1951), Los instrumentos de la música afrocubana (19521955), Historia de una pelea cubana contra los demonios (1959); además de dos publicaciones póstumas: Nuevo catauro de cubanismos (1974) y Los negros curros (1986).

Fernando Ortiz es el sociólogo cubano que ha hecho el aporte teórico más importante y original en este campo de las ciencias del hombre. Nos referimos al concepto de transculturación, que dio a conocer en su libro Contrapunteo cubano del tabaco y el azúcar (1940). Por sus excelencias literarias este libro es uno de los clásicos de la ensayística cubana.

La definición de transculturación que da Ortiz es aplicable por igual a todos los grupos humanos que se introdujeron o fueron introducidos en Cuba. Dicho concepto posee una actualidad y sentido revolucionario evidente, al oponerlo conscientemente al enfoque neocolonial que provee la aculturación, aporta una perspectiva de liberación nacional para el Tercer Mundo, dirigida a la defensa y revalorización de las culturas consideradas primitivas e inferiores por los poderes centrales; es una sintesis admirable de dos temas recurrentes en nuestros pensadores sociales: la identidad nacional y la influencia semicolonial. Parte de la importancia del concepto de transculturación radica en que al acuñarlo en 1940 el lo hizo trascendiendo la noción de aculturación (acculturation), concepto entonces en boga dentro de la antropología positivista europea para definir los efectos culturales en sus colonias. La aculturación era la idea de que la imposición cultural lograba desplazar gran parte de los imaginarios culturales originales, hasta el punto de neutralizarlos y sustituir su cultura por la del colonizador. En cambio, para explicar la identidad cubana y latinoamericana en el marco del colonialismo europeo, Ortiz propone la transculturación que nombra el proceso de resistencias y permeabilidades de una cultura, en sus prácticas y comportamientos, a la que se le había impuesto otra cultura.

La variada, rica y dramática historia de nuestra zona geográfica desde la época en que llegaron los primeros "descubridores" en el siglo XV, con sus signos "civilizadores" y la convirtieron en lo que Juan Bosh ha denominado "frontera imperial", hasta estos inicios del nuevo milenio, es el sustrato del mestizaje provocado por los pueblos que por diferentes vías se han establecido en el área, en condiciones bien diversas, ya sea dominador (conquistadores) o dominados (pueblos aborígenes o esclavos africanos). Este largo proceso marcará entonces, los avatares por los que ha 
transitado la identidad cultural de la región. Visto así, mestizaje, identidad y cultura son signos de un marcado carácter polisémico y aportador de una singularidad en la diversidad cultural de "Nuestra América".

Aunque los estudios del sabio cubano miran directamente a los fenómenos de la isla, no es menos cierto que sus abarcadores juicios son aplicables a los estudios culturales de cualquier región y especialmente a América Latina, cuyo proceso de conformación de su cultura es muy similar al investigado por Ortiz en el caso cubano. No puede emprenderse un estudio medianamente serio sobre la identidad sin acudir a las investigaciones orticianas, lo cual implica un reconocimiento al científico, al sociólogo, al etnólogo, en fin al hombre, que de una manera tan decisiva, contribuyó a una clara definición de la identidad cubana, partiendo de un profundo análisis y una demostración científica en los componentes esenciales que configuran lo cubano en sus múltiples facetas.

Estos difíciles años de guerra y la intervención norteamericana marcarán, sin dudas, su personalidad, seguidor del positivismo de perspectivas radicales, participa por el Partido Liberal, en la politica cubana de las primeras décadas e incluso fue representante a la Cámara en 1917. Asqueado de los manejos de la época en el plano político la abandona en 1922, para integrarse a los estudios de los grandes reformistas, la cultura y la ciencia cubana hasta la primera mitad del XIX. Esta búsqueda en la "virtud doméstica" cubana quedará claramente plasmada en su consigna: "Fe viva en la cultura, energía incansable en la acción y disciplina cívica en la conducta", lanzado en su contradictorio y angustiado discurso "Seamos hoy como fueron ayer" de 1914.

El despertar de la conciencia nacional a partir de 1920, la "década crítica" a decir de Marinello, y la aparición de figuras como Mella, Villena, Emilio Roig, Carpentier, la aparición de revistas como Avance, etc., influyen en que Ortiz evolucione hacia posiciones críticas de mayor madurez, se vincula a la izquierda intelectual en formación, a la par que continúa su programa de actualización de la cultura y funda la Institución Hispano-Cubana de Cultura (1926), que juega un importante papel en la reafirmación de la cultura y la enseñanza.

Con Machado en el poder y las trágicas consecuencias de su mandato, Ortiz va al exilio, donde publica varios artículos sobre Cuba, aborda la injerencia norteamericana como uno de los males cubanos y continúa su profundización en la historia cubana y africana. Estos años 30 será momento decisivo para gestar su monumental obra Contrapunteo 
cubano del tabaco y el azúcar. Al caer la dictadura machadista regresa a Cuba, reanima la Institución Hispano-Cubana de Cultura, así como la revista Bimestre Cubano, continúa su empeño en el estudio de la formación étnico-cultural del país, la realidad y el fruto de lo afrocubano. Funda en 1937 la Sociedad de Estudios Afrocubanos, ya en estos tiempos su obra se perfila como un arma ideológica contra la discriminación social y por la consolidación de la sociedad mestiza nacional.

El pensamiento cubano en los inicios del siglo XX es esencial para entender el fenómeno de la cubanidad y, especialmente, sus factores humanos. Así Fernando Ortiz, Jorge Mañach, Elías Entralgo, Alejo Carpentier y Juan Marinello, entre otros, contribuyen a la comprensión de nuestra conciencia social y a la identidad cultural compartida con los latinoamericanos. Innumerables son los aportes de Ortiz a los estudios culturales, todos hoy de plena vigencia, pero sin dudas donde radica su mayor trascendencia es su concepto para definir el proceso formativo de una nueva cultura en Cuba, a partir de los intercambios de culturas que se producen.

Para explicar este fenómeno, el sabio cubano crea el neologismo transculturación, por lo cual expresa: "Por aculturación se quiere significar el proceso de tránsito de una cultura a otra y sus repercusiones sociales de todo género, pero transculturación es vocablo más apropiado para expresar los variadísimos fenómenos que se originan en Cuba por las complejísimas transmutaciones de culturas que aquí se verifican, sin conocer los cuales es imposible entender la evolución del pueblo cubano, así en lo económico como en lo institucional, jurídico, ético, religioso, artístico, lingüístico, psicológico, sexual y en los demás aspectos de su vida" (ORTIZ, 1983, p. 86). En este sentido Ortiz no obvia, a la hora de elaborar su teoría, otros criterios que sobre el tema abordan otros investigadores.

Así tiene en cuenta el concepto de desculturación, como sinónimo de pérdida o desarraigo de una cultura, así como la neoculturación o creación de nuevos fenómenos culturales. Ambos conceptos entroncan directamente con el concepto de aculturación. Términos todos opuestos, sin dudas, al neologismo de Ortiz.

Existe una gran diferencia entre los términos aculturación y transculturación. El primero solo analiza cómo en los procesos interculturales que se producen, se va dando una pérdida de las culturas dominadas dentro de las culturas dominantes, lo que implica entonces la falta de un reconocimiento hacia esas culturas "menores". Si tomamos como válido este concepto, entonces no podríamos hablar de una cultura 
cubana, mexicana, etc., ni latinoamericanas, hablaríamos de una cultura, digamos española en América Latina o, en su defecto, en un determinado país, atendiendo a los conceptos de la identidad vertical que "se forma desde arriba, por acción hegemónica de dominación o la conquista y colonización expansiva en que el pueblo vencedor impone sus patrones y modo de vida culturales al dominado o vencido" (ROJAS GÓMEZ, 1991, p. 119).

Aculturación es un término racista, que en los momentos actuales de procesos globalizadores y hegemónicos toma una nueva dimensión. El "inculto" (emigrante, esclavo, aborigen, etc.) ha de recibir los beneficios de "nuestra cultura" (ya puede entenderse cuál) y debe cambiar para su "bien" y convertirse en "uno de nosotros" (ya sabemos que significado tiene aquí nosotros). Por tanto, el neologismo, venido del inglés (¡qué casualidad!) lleva implícito un conjunto de conceptos morales, normativos, éticos que ha tenido un significado desastroso para las minorías.

Por su parte, transculturación es un fenómeno más complejo y completo que implica intercambios de culturas, sumas complejísimas que va dando origen a algo nuevo y diferente. La transculturación es un parto de un nuevo ser donde padre y madre, en su copulación, han dado origen a un tercero que tiene de ambos, pero es diferente porque es nuevo, por tanto, en ello se cumple la idea de que en la cultura latinoamericana se da la unidad dentro de la diversidad. Sin dudas el símil de Ortiz "Cuba es un ajiaco" sigue siendo válido para todo el proceso formativo cultural de América Latina, por tanto, en el desarrollo de este fenómeno es aplicable entonces el término de lo que Rojas Gómez llama "identidad horizontal", o sea, la conformada por los diferentes aportes de uno y otro que dan lugar a lo nuevo y que sin dudas coincide con lo planteado por Ortiz. Para él la transculturación es un proceso complejo de transformaciones en el que suceden momentos de aculturación, deculturación y neoculturación; de pérdidas, reencuentros, selecciones e incorporaciones (RAMA, 1982, p. $39)^{68}$.

Implícitamente Ortiz nos está diciendo que a pesar de que la cultura pueda ser desconcertante en su complejidad, ésta aparece a partir del proceso de tres principios equivalentes al nacimiento, la muerte y la supervivencia, y que él observaba como aculturación, deculturación y

${ }^{68}$ Este autor define cuatro operaciones esenciales en la transculturación orticiana: pérdidas, selecciones, redescubrimientos e incorporaciones. 
neoculturación. En este sentido, la propuesta orticiana nos recuerda a Heráclito en tanto que lo único que permanece es el cambio: en el espacio de la cultura ese cambio es transformación con decisión, es decir, con autoconciencia.

Así, el gran mérito de Fernando Ortiz es establecer una reconstrucción general e incluso transtemporal del sistema de la cultura, al tiempo que evidencia lo falaz de una monocultura y su demanda homogénea. No menos importante es que al hacerlo dignifica o da sentido a la heterogeneidad y alteridades de una identidad emergente latinoamericana; levanta cabeza frente a imposiciones provenientes de la hegemonía colonial, trascendiendo el vicio dicotómico opresor-oprimido. "[...] en Cuba [...], como en pueblo alguno de América, su historia es una intensísima, complejísima e incesante transculturación de varias masas humanas, todas ellas en pasos de transición. El concepto de transculturación es cardinal y elementalmente indispensable para comprender la historia de Cuba y, por análogas razones, la de toda la América en general" ${ }^{69}$. Recibió el reconocimiento en su época del eminente sociólogo y etnólogo Bronislaw Malinowski, quien conoce a Fernando Ortiz durante un viaje a La Habana, en 1929, y donde el sabio cubano le comentó su nuevo vocablo técnico para reemplazar expresiones corrientes como "cambio cultural", "aculturación", "difusión", etc.

Después de un profundo análisis y no el hecho simple del cambio por el cambio, Malinowski llega a la conclusión de que

Para describir tal proceso del vocablo de latinas raices transculturación, proporciona un término que no contiene la implicación de una cierta cultura hacia la cual tiene que tender la otra, sino una transición entre dos culturas, ambas activas, ambas contribuyentes con sendos aportes, y ambas cooperantes al advenimiento de una nueva realidad de civilización (MALINOWSKI en ORTIZ, 1983, p. XXXIII) ${ }^{70}$.

\footnotetext{
${ }^{69}$ Transculturación. Referente de sentido frente a la aculturación Yanin Guisando Dorado • Historiadora del Arte. Investigadora del Cenidiap. Revista Digital Cenidiap, Julio-Diciembre, 2009.

${ }^{70}$ Recomendamos una lectura de esta excelente introducción para comprender mejor el aporte de Ortiz a los estudios culturales en América Latina y sobre todo por la vigencia actual de estos criterios, contra los procesos globalizadores que se tratan de imponer en la actualidad.
} 
El neologismo de Ortiz ha sido reconocido por innumerables investigadores a la hora de hablar de los procesos formativos de la cultura latinoamericana. Así, por ejemplo, Fernando Aínsa señaló: "La «nacionalización» o «americanización» consiguiente de escuelas, modos de pensar, direcciones estéticas, no deben verse como una simple copia mimética de un modelo, sino como un apasionante ejemplo de la «transculturación» de que ha sido capaz Iberoamérica.

El modernismo constituyó uno de sus mejores ejemplos, pero, como ha dicho Dámaso Alonso "cada época tiene su «razón estética» aunque unas épocas no entiendan la razón de otras” (AÍNSA en ORTIZ, 1983, p. 37). A nuestro modo de ver, el neologismo de Ortiz, de manera auténtica y precisa, expresa el fenómeno del nacimiento de la cultura cubana y, sin dudas, coadyuva a entender nuestra identidad dentro de la heterogeneidad que la ayudó a originar y conformar tal como es y que puede implicar hablar de la cubanidad y lo cubano, pero el término del tercer descubridor de Cuba va más allá de las fronteras nacionales. Sus estudios, vigentes aún, son aplicables y válidos para explicar el devenir de la identidad cultural de nuestros pueblos "al Sur del Río Bravo". Sin dudas el aporte de Ortiz implica una "dialéctica intercultural" de plena vigencia actual.

Esta defensa tan singular que realizó el sabio cubano no soslaya, sino que reafirma nuestra identidad cultural caribeña y latinoamericana, pues no pasa por alto las herencias y parentesco que acercan a las culturas del continente a lo mejor de la tradición universal. La propuesta de Ortiz ha ganado una nueva dimensión con la función emancipadora de la cultura (esa vía propuesta por Martí) pero también lo es viable en su carácter humanizador y a la vez desalienante que el proceso cultural lleva implícito en sí mismo.

En sus acuciosos estudios sobre la música popular cubana, donde insiste en buscar las verdaderas raíces, cuya teoría se opone a los perjuicios sociales y raciales de la época que le tocó vivir en la neocolonia cubana, el investigador cubano pone el dedo en la llaga sobre un problema: el acercamiento o penetración en la cultura oficial cubana de la norteamericana, fenómeno superado en Cuba a partir de 1959, pero desafortunadamente cada vez más recurrente en América Latina en los tiempos que corren. Así, afirma:

$\mathrm{Si}$ no tan grave como el imperialismo económico, que succiona la sangre del pueblo cubano, es también disolvente 
el imperialismo ideológico que le sigue. Aquel le rompe su independencia económica; este le destroza su vida moral. El uno le quita el sostén; el otro el alma. Tratemos, pues, de conocernos a nosotros mismos y de aquilatar nuestras esencias, para mantener puras las de valor sustantivo y perenne y apartar aquellas que, nuestras o extrañas, sean ya de pútrida ranciedad o traigan a nuestra vida una letal ponzoña (ORTIZ, 1934, p. 115-116).

Hay, sin dudas, en este análisis, un enfoque verdaderamente científico del problema cubano de la época, al mirar como la penetración norteamericana, en las bases esenciales de la economía cubana (azúcar, minería, empresas telefónicas, etc., en manos de empresas norteamericanas) la hacen ser totalmente dependientes del "vecino del Norte" convirtiendo a Cuba en una neocolonia. Esta dependencia económica penetra profundamente la cultura cubana, por tanto, el juicio de Ortiz es acertado ya que es la época en que el cine norteamericano, la música y en general el "modo de vida norteamericano" ha calado la conciencia cubana en detrimento de lo nacional.

En este sentido la posición de Ortiz entronca con lo mejor del pensamiento antimperialista que tuvo en José Martí a su máximo exponente en el siglo XIX, y en Mella, Marinello, Carpentier, Ortiz, dignos continuadores.

La más genuina intelectualidad cubana intentó sobreponer lo cubano a lo extranjero. No es raro, entonces, que esta época de a la luz nuevos géneros musicales como el feeling, el cha-cha-chá y el mambo, mientras que los principales pintores de la época: Lam, Portocarrero, Amelia, Mariano, salgan a la búsqueda de una identidad nacional a partir de lo negro, la arquitectura colonial, los gallos, las frutas.

En la literatura, un importante grupo de poetas como Lezama Lima, Cintio Vitier, Fina García Marfuz, etc., busquen las raíces cubanas a partir de sus Orígenes, plasmados en la importante revista de igual nombre. Por todo esto Cintio Vitier, en las palabras finales de su ya mítico ciclo de conferencias sobre lo cubano en la poesía, que no por gusto se organizó en estos años, afirmaba: "somos víctimas de la más corruptora influencia que haya sufrido jamás el mundo occidental" (VITIER, 1999, p. 8) refiriéndose en este caso a la presión y sometimiento de la sociedad cubana a la dependencia e influencia norteamericana. 
Desde la perspectiva de la educación, como contrapartida a la penetración de los paradigmas yanquis en los grupos privilegiados que educaba a sus hijos en escuelas norteamericanas y que copiaba sus costumbres y modas, un grupo de maestros significativos trató de mantener un sentido nacional ante esta penetración. Al respecto el recordado pedagogo Carlos de la Torre afirmaba: "Sean nuestros libros de texto cubanos, por autores cubanos, tomados de nuestros patriotas, de nuestras guerras libertadoras, de nuestra hermosa naturaleza [...] Evitemos que libros extranjerizantes deformen nuestra nacionalidad" (TORRE, 1995, p. 58).

Otro aporte orticiano a los estudios culturales y que guarda relación con el proceso de la identidad cultural es la "Teoría de las Transvaloraciones" de la cultura, elaborada por R. B. Marett, dada a conocer en Londres en el libro Psychology and Folklore. Ortiz la hace suya y la aplica al nuevo concepto de transculturación. Según la teoría, los cambios en la cultura pueden ser horizontales o verticales.

La transvaloración vertical consiste en el cambio de posición o rango de un rasgo cultural que puede ascender o descender, proceso denominado metátesis. Según Ortiz se dan reiteradamente en la música criolla de Cuba ... "del retozo de las musas negras con las musas blancas ha ido surgiendo danzas amulatadas, ricas de expresión como la habanera, el danzón, la rumba, el son, la conga, el mambo, el cha-cha-chá, etc., y todas ellas han experimentado el mismo fenómeno de metátesis: un tiempo son rechazadas como indecorosas y propias de la «gentualla» [...] pero las danzas del vulgo se van adecentando y revistiendo en tanto para lograr un reajuste socialmente ventajoso, y las gentes cautelosas van transigiendo otro tanto para gustar las sabrosuras del fruto prohibido. Así, con menguas de picardía y aumento de tolerancia, los bailes de la gente de «escaleras abajo» van subiendo los peldaños sociales hasta penetrar en los salones y compartir los esparcimientos de las gentes de "escaleras arriba» (ORTIZ apud. IZNAGA, 1989, p. 80).

Este proceso es factible de verse en diferentes expresiones de la cultura de América Latina. Los pueblos de esta parte del mundo han sentido la necesidad, a partir de la independencia, de buscar sus raíces más autóctonas como vehículo de reafirmación de independencia y, por tanto, de identidad, así se exalta lo peculiar en cada caso de minorías nacionales o étnicas, que alcanzan rangos superiores a través de este proceso descrito por Ortiz. 
La transvaloración también puede ser horizontal, al cual Ortiz denomina metalepsis, y en este caso el cambio solo está en el sentido; por ello dice: "Así ocurre a veces con la música religiosa que, al perderse para la liturgia [...] cae a la profanidad [...] Tal va aconteciendo en Cuba con la música frenética, a cuyo ritmo son reverenciados las potencias sobrehumanas de los negros de la nación. Todavía se canta y baila a los orishas negros en los templos de la santería, con los mismos tambores que en las tierras de Guinea, pero algunas de sus melodías y ritmos ya han sido absorbidos por las músicas criollas que, con rimbombancias de bongó y estridencias de cornetín traducen los sacros ritos danzarios de los dioses negros a bailes salaces de «todos los colores»" (idem, p. 81).

Ortiz completa su concepto de transculturación demostrando que no solo es factible a seres humanos, sino incluso en instituciones sociales y no siempre en los pueblos inferiores culturalmente (como afirmaron algunos estudios discriminatorios) sino incluso entre los más adelantados. Por ello el fenómeno va de un plano a otro, de abajo a arriba y viceversa (metátesis) o de una posición a otra sin cambio ambiental (metalepsis). Así se transcultura el negro, el blanco o una mitología, un ritmo, o un tambor. 71

La adopción de esta teoría, por parte de Ortiz, amplía el concepto de transculturación y da cabida en él a un criterio clasista en el que, según la teoría marxista, en estas sociedades divididas en clases se dan dos culturas, una "dominante" y otra "dominada", que en el caso de Ortiz está marcada por un carácter esencialmente étnico (blancos y negros en Cuba) entendible en Cuba donde siempre se dio el fenómeno.

Con sus aportes Ortiz da una nueva dimensión a la cultura cubana y a nuestra historia, pues definió los elementos constitutivos esenciales, propiciando una integración étnico-cultural. Con sus estudios destruyó mitos y prejuicios y legó puntos de partida para futuros estudios, demostró que la cultura nuestra tiene un basamento esencialmente ético, comprometido con la justicia y de un largo camino de constantes encontronazos que nos propicia una identidad, surgida desde abajo, fruto del intercambio cultural de conquistadores y conquistados, pero que

\footnotetext{
${ }^{71}$ Para un completo estudio de estas problemáticas, que amplian los conceptos y valoraciones sobre la identidad cultural, sugerimos además del texto de Diana Iznaga, aqui citado, los textos de Fernando Ortiz: Los instrumentos de la música afrocubana, La antigua fiesta afrocubana del Día de Reyes," La transculturación blanca de los tambores de los negros", El engaño de las razas, asi como Historia de una pelea cubana contra los demonios, todas las cuales son demostrativas de criterios de suma actualidad.
} 
enarbola a toda su amplitud ante el mundo, la humanidad y el valor del hombre mestizo. Fue un gran aporte del sabio cubano el saber encontrar lo diverso de lo humano, palpable en la cultura de componentes africanos, cuyo estudio y reafirmación establece un discurso de reconocimiento de la identidad del hombre, hoy de total vigencia.

Al definir la transculturación como un fenómeno desintegrativo e integrativo a la vez, en los elementos sustanciales de la cultura y de la vida, daba un nuevo espacio para valorar la identidad cultural, no solo cubana, sino latinoamericana, a su justo devenir histórico. Como a principios del siglo XX con Fernando Ortiz, en estos albores del siglo XXI el proceso de aculturación vuelve a tener relevancia, ahora con la hegemonía cultural neoliberal. La aculturación es el fenómeno de recepción y asimilación pasiva, de una cultura a la que se le es impuesta otra; la aculturación sería la aceptación de la imposición sin resistencia, neutral o apáticamente. Centrada en la homogeneización, la aculturación propicia una identidad casi esquizofrénica, una pérdida de identidad nacional, de etnia, de clase y de realidad política, de ahí la importancia y vigencia del concepto de transculturación, como polo opuesto al proceso de aculturación, que dignifica o da sentido a la heterogeneidad y alteridades de una identidad emergente latinoamericana, resaltando lo autóctono de nuestro continente.

\section{Conclusiones}

Homogeneizar, imponer una cultura como única y mejor, no reconocer las diferencias, es una herramienta de las estructuras verticales de poder, de un control social que se fundamenta en la vieja y acartonada dicotomía opresor-oprimido; en cambio, reconocer las heterogeneidades, las diferencias y alteridades, y por ende que la constitución de la cultura es compleja, potencialmente transcultural y con ello cambiante $y$ transformativa, permite abrir nuevas perspectivas que, asimismo, nos acercan a una ética realista y con ello a la construcción de un mundo más justo con vidas más interesantes y dignas de ser disfrutadas.

La identidad cultural presupone un conjunto teórico- práctico de formas y elementos disímiles y a la vez similares, poseedor de un carácter dinámico, transformador y enriquecedor que significa una identificación concreta del hombre y de un espacio que se erige en un proceso cambiante debido a que brota de un pasado, se afianza en un presente y posee 
proyección futura por su constante renovación y enriquecimiento. Concepto de origen latinoamericano, constituye su proyección, a partir del mas revolucionario pensamiento de la región durante toda su historia, un proceso de reafirmación contra los centros hegemónicos de poder que intentaron e intentan la imposición de una monocultura universal que lastra tanto la identidad nacional, como regional de Nuestra América.

El nombre de Fernando Ortiz, está estrechamente vinculado, por sus profundos estudios, al proceso de desentrañar los caminos de la identidad cultural latinoamericana, pues los mismos parten de los componentes esenciales que la misma posee. El neologismo transculturación de su propia invención, implica una dialéctica intercultural de plena vigencia actual, que al definirla como un fenómeno integrador y desintegrador a la vez, da un nuevo espacio para justipreciar la identidad cultural latinoamericana, en tiempos de una globalización neoliberar que pretende opacar lo autóctono de nuestra región, de ahí su plena vigencia en el siglo XXI.

\section{BIBLIOGRAFÍA}

ANTOLOGÍA. Pensamiento y política cultural cubanos. Editorial Pueblo y Educación, La Habana, 1986, tomo I.

BARNET, Miguel. La fuente viva. Editorial Letras Cubanas, La Habana, 1983.

BOLIVAR, Simón. Obras Completas. Vol 3, Alonso, Madrid, sf.

BOHÓRQUEZ, M.; CARMEN L. Francisco de Miranda, Precursor de las independencias de la América Latina. Editorial Ciencias Sociales, La Habana, 2003.

BUENO, Gustavo. El mito de la cultura. Editorial Prensa Ibérica, S. A., Barcelona, España, 1996.

CASANOVA; Pablo (coord.). Cultura y creación intelectual en América Latina, (Coordinador Pablo González Casanova) Editorial Ciencias Sociales, La Habana, 1990. 
. Memorias del II Taller de Pensamiento Cubano. Ediciones CREART, La Habana, 1996.

. Memorias del III Taller de Pensamiento Cubano. Editorial Capiro, Santa Clara, 1999.

. Filosofía en América Latina. Editorial Félix Varela, La Habana, 1998.

. Filosofía y sociedad. Editorial Félix Varela, La Habana, 2000.

Pensamiento español y latinoamericano contemporáneo. Editorial Feijóo, Universidad Central "Marta Abreu" de Las Villas, Santa Clara, 2002.

DICCIONARIO DE LA LITERATURA CUBANA. Instituto de Literatura y Lingüística, ACC. Editorial Letras Cubanas, La Habana, 1984.

DOSSIER. Cultura y Desarrollo. Consideraciones para un debate. Instituto Cubano del Libro, La Habana, 1999.

FERNÁNDEZ RETAMAR, Roberto. Calibán. Apuntes sobre las culturas de Nuestra América. Editorial La Pléyade, Buenos Aires, 1973.

FLORES, Eduardo. Las dos culturas: aliadas por necesidad, en Cuadernos Nacionales, Universidad de Panamá, Segunda Época, \# 2, 2003.

GARCÍA CANCLINI, Néstor. Consumidores y ciudadanos. Conflictos multiculturales de la globalización. Editorial Grijalbo, México, 1975.

GARCÍA ALONSO, M.; BAEZA, C. Modelo teórico para la identidad cultural. Centro Juan Marinello, La Habana, 1996.

GUISANDO DORADO, Yaima. Transculturación. Referente de sentido frente a la aculturación. Revista Digital Cenidiap, Julio-Diciembre, 2011.

GUADARRAMA, Pablo. Valoraciones sobre el pensamiento filosófico cubano y latinoamericano. Editora Politica, La Habana, 1988. 
_-_-_. Humanismo y autenticidad en el pensamiento latinoamericano. Universidad INCCA, Colombia, 1997.

GUADARRAMA, Pablo y N. PERELEGUIN. Lo universal y lo especifico en la cultura. Santa clara, Cuba; Bogotá, Colombia, 1998.

GUADARRAMA, Pablo y M. ROJAS GÓMEZ. El pensamiento filosófico en Cuba en el siglo XX: 1900-1960. Editorial Félix Varela, La Habana, 1998.

IZNAGA, Diana. Transculturación en Fernando Ortiz. Editorial Ciencias Sociales, La Habana, 1989.

LEZAMA LIMA, José. La expresión americana. Editorial Letras Cubanas, La Habana, 1988.

LÓPEZ SEGRERA, F. Cuba: Cultura y sociedad. Editorial Letras Cubanas, La Habana, 1989.

MALINOWSKI, Bronislaw. "Introducción", en ORTIZ, Fernando. Contrapunteo cubano del tabaco y el azúcar. Editorial de Ciencias Sociales, La Habana, 1983.

MARTÍ, José. Obras escogidas en tres tomos. Colección Textos Martianos. Editorial Ciencias Sociales, La Habana, 1992.

. Obras Completas. Editorial Nacional de Cuba, La Habana, 1964, tomo 8 .

Nuestra América. Edición Crítica. Centro de Estudios Martianos, La Habana, 2000.

ORTIZ, Fernando. Contrapunteo cubano del tabaco y el azúcar. Editorial de Ciencias Sociales, La Habana, 1983.

. De la música afrocubana. Un estímulo para su estudio, en Universidad de La Habana, La Habana, t. 1, no. 3, mayo-jun., 1934. 
. La transculturación blanca de los tambores de los negros en Islas, Santa Clara, vol. 5, no. 1, jul.-dic., 1962.

1975.

. El engaño de las razas. Editorial de Ciencias Sociales, La Habana,

- Historia de una pelea cubana contra los demonios. Editorial de Ciencias Sociales, La Habana, 1975.

. Los instrumentos de la música afrocubana. Publicaciones de la Dirección de Cultura del Ministerio de Educación, La Habana, t. 1, 1952.

- La antigua fiesta afrocubana del Día de Reyes. Ministerio de Relaciones Exteriores, La Habana, 1969.

PINEDO, Javier. Una trayectoria intelectual. Entrevista con Arturo Andrés Roig, en Solar, estudios latinoamericanos, Santiago de Chile, 1993.

PONCE, Aníbal. De Erasmo a Romain Rolland. Humanismo burgués y humanismo proletario. Editorial Futuro, Buenos aires, 1962.

PORTUONDO, José A. Bosquejo histórico de las letras cubanas. Ediciones del MINED, La Habana, 1962.

PRIETO, Abel. Cultura, cubanidad y cubania. Conferencia La Nación y la Emigración, en Ensayos sobre identidad, Ciencias Sociales, 1999.

RAMA, Ángel. Transculturación narrativa en América Latina. México: Siglo XXI, 1982.

ROJAS GÓMEZ, Miguel. El problema actual de la identidad cultural de América Latina y la vigencia de la solución martiana, UANL, Monterrey, México, 1994.

- La mundialización y la necesidad de reconstrucción de la identidad cultural, en J. Alvarado (ed.), Mundialización y liberación, UCA, Managua, Nicaragua, 1996. 
, et al. La polémica sobre la identidad. Editorial de Ciencias Sociales, La Habana, 1997.

. Redefinición y teoría de la identidad cultural, en Islas, año 41, no. 119, ene-mar., 1999.

. La identidad cultural como sistema teórico en Humanistas, Centro de Estudios Humanísticos, UANL, Monterrey, México, 2000.

SAMBRANO, Mario. Identidad, tradición y autenticidad. Tres problemas de América Latina. CELORBG, Caracas, Venezuela, sf.

SERRANO CALDERAS, Alejandro. La unidad en la diversidad. Hacia una cultura del consenso. Editorial San Rafael, Managua, Nicaragua, 1993.

TORRES, Carolina de la. Psicología latinoamericana. Entre la dependencia y la identidad. Editorial Félix Varela, La Habana, 1995.

UBIETA Gómez, Enrique. Ensayos de identidad. Editorial Letras Cubanas, La Habana, 1993.

VITIER, Cintio. "Ensayo", en DOSSIER. Cultura y Desarrollo. Consideraciones para un debate. Instituto Cubano del Libro, La Habana, 1999.

ZEA, Leopoldo. Descubrimiento e identidad latinoamericana, UNAM, 1990.

Recebido em: 14/06/2016

Aceito em: 30/06/2016 